\title{
Improvement of mechanical properties in SUS304L steel through the control of
}

\section{bimodal microstructure characteristics}

Zhe Zhang $^{\text {a }}$, Sanjay Kumar Vajpai ${ }^{\text {b }}$, Dmitry Orlov ${ }^{\text {b* }}$, Kei Ameyama ${ }^{\text {c }}$

${ }^{\mathrm{a}}$ Graduate School of Science and Engineering, Department of Mechanical Engineering,

Ritsumeikan University, 1-1-1 Noji-higashi, Kusatsu, Shiga 525-8577, Japan

${ }^{b}$ Research Organization of Science and Technology, Ritsumeikan University, 1-1-1

Noji-higashi, Kusatsu, Shiga 525-8577, Japan

${ }^{\mathrm{c} D e p a r t m e n t}$ of Mechanical Engineering, Faculty of Science and Engineering,

Ritsumeikan University, 1-1-1 Noji-higashi, Kusatsu, Shiga 525-8577, Japan

*Corresponding author: Research Organization of Science and Technology,

Ritsumeikan University, 1-1-1 Noji-higashi, Kusatsu, Shiga 525-8577, Japan

Tel.: +81 77561 2749; Fax: +81 77561 2665. E-mail: orlov@fc.ritsumei.ac.jp

(C) 2014. This manuscript version is made available under the Elsevier user license

http://www.elsevier.com/open-access/userlicense/1.0/ 


\section{Abstract}

The present work deals with achieving improvement in the mechanical properties of SUS304L stainless steel through the application of a unique microstructure design termed as 'Harmonic structure', and establishing a co-relationship between various microstructural characteristics and mechanical properties. Harmonic structure essentially means a bimodal grain size distribution with a specific periodic arrangement of coarse- and ultrafine- grain fractions. SUS304L stainless steel samples having such microstructure were fabricated by a powder metallurgy route involving the mechanical milling of pre-alloyed steel powder followed by spark plasma sintering. Due to these peculiar microstructural characteristics, the harmonic-structured SUS304L stainless steels demonstrated a winning combination of high strength, large uniform elongation, and large total elongation to failure, simultaneously. It was also found that the fraction of a shell area (a three-dimensional continuously connected network of ultrafine-grained structure) is an important parameter controlling the balance of the mechanical properties of the harmonic-structured SUS304L steel compacts.

Keywords: Stainless steel; Microstructure design; Bimodal grain structure; Harmonic structure; Mechanical property. 


\section{Introduction}

Austenitic stainless steels are among the most important structural materials for automotive components and high-pressure vessels due to their excellent corrosion resistance and sufficient strength. However, in order to remain the material of choice for these component manufacturers, the structural efficiency of stainless steels, and strength in particular, should be improved. Grain refinement is a well-known approach for strengthening metals and alloys [1-5]. In particular, ultrafine-grained (UFG) steels have demonstrated superior strength and hardness compared to their coarse-grained counterparts [6-12]. However, the limited ductility of UFG materials, which is caused by the plastic instability at the early stage of deformation, is a major barrier to their widespread commercial applications [13-15]. Therefore, it is imperative to achieve the improvement of both the mechanical properties, i.e. a combination of high strength and good ductility, in the UFG steels to make them really attractive for the aforementioned applications.

In recent years, it has been demonstrated that materials having bimodal grain size distribution possess high strength and a reasonable ductility [16-20]. In these microstructures, ultrafine grains provide increased strength, while coarse grains ensure retained ductility [21-23]. Bulk metals and alloys having bimodal grain size distribution have been successfully synthesized by following two approaches: 
(i) Ingot metallurgy route based on thermo-mechanical treatment involving severe plastic deformation (SPD) followed by an appropriate thermal annealing under controlled conditions [16, 18, 19]; and

(ii) Powder metallurgy route based on mechanical milling (MM) of powders followed by the consolidation of powder mixture consisting of milled powder and as-received coarse-grained powders in desired relative amounts [23, 24].

The main benefit of the second approach is that a tailored bimodal structure can be conveniently achieved using a desired ratio of starting powders, and the mechanical properties can be optimized using the appropriate bimodal structure [25, 26].

Recently, Ameyama and co-workers proposed a novel microstructure design concept called "harmonic structure" [20, 24, 27-31]. Effectively, this is an exquisite microstructure design based on bimodal grain size distribution, wherein the areas of coarse-grained structure (or "cores") are enclosed in a three-dimensional continuously connected network of ultrafine-grained structure (or "shell"), see Fig.1. Herein, 'coarse-' and 'ultrafine-' refer to grain sizes in a range of $\geq 10 \mu \mathrm{m}$ and $\leq 5 \mu \mathrm{m}$, respectively. The concept of harmonic structure design has been successfully applied in a variety of materials, such as pure $\mathrm{Ti}[27,32]$ and $\mathrm{Cu}$ [20], alloy Ti-6Al-4V [24], and two-phase steel SUS329J1 [31]. All these materials demonstrated a winning 
combination of strength and ductility as compared to their coarse-grained as well as UFG counterparts. However, there was no investigation of the parameters of harmonic structure that ensure such a mechanical behaviour.

Therefore, the present work has two major goals: (i) to investigate the possibility of harmonic structure formation in a new material, which is a stainless steel SUS304L; and (ii) to investigate the parameters of harmonic structure (e.g. ratio of core/shell volume fractions) that control the mechanical properties. The harmonic structure was fabricated in a stainless steel SUS304L by a powder metallurgy approach, which involves mechanical milling of the steel powder followed by its consolidation using spark plasma sintering (SPS). The microstructural characteristics and mechanical properties of the harmonic-structured SUS304L steel compacts are presented and discussed. Finally, the effect of core/shell volume fractions on the mechanical properties of the harmonic-structured compacts is analysed and compared to those of "homogeneous" coarse-grained and ultrafine-grained bulks.

\section{Experimental material and procedures}

The SUS304L steel powder, prepared by plasma rotating electrode process (PREP), was used as a starting material. The chemical composition of the initial PREPed powder 
is shown in Table 1. Average particle size in the initial powder was approximately $120 \mu \mathrm{m}$. Mechanical milling was carried out in a Fritch P-5 planetary ball mill using SUS304 steel vial and balls ( $5 \mathrm{~mm}$ diameter). The milling was carried out under argon gas atmosphere at room temperature, wherein the ball-to-powder weight ratio was maintained at $2: 1$. The powder mixture was milled for $180 \mathrm{ks}(50 \mathrm{~h})$ and $360 \mathrm{ks}(100 \mathrm{~h})$ at a constant milling speed of $200 \mathrm{rpm}$. Subsequently, the powders were sintered by SPS under 50MPa for $3.6 \mathrm{ks}(1 \mathrm{~h})$ at $1173 \mathrm{~K}$.

The microstructure observations were carried out by scanning electron microscopy (SEM) in a field-emission gun FE-SEM Hitachi SU6600 microscope operating at 20kV. The microscope was fitted with HKL NordlysMax electron backscatter diffraction (EBSD) detector. The micrographs were acquired using both secondary and backscattered electron imaging, SE and BSE, respectively. In addition, EBSD technique was utilized for the quantitative analysis of microstructure. Hereafter, term "grain" will refer to crystallite areas predominantly surrounded by HABs (High Angle Boundaries with misorientation angle at least $\theta \geq 15^{\circ}$ ). The "grain size" $<\mathrm{d}>$ was determined as an equivalent diameter of such areas. Standard metallographic procedures were employed for the SEM and EBSD sample preparation with final polishing using colloidal silica suspension.

The mechanical properties were examined in hardness and tensile tests. The 
specimens for tensile tests were machined by wire-spark cutting to a gauge length of $3 \mathrm{~mm}$ and a cross-section area of $1 \times 1 \mathrm{~mm}^{2}$. Tensile tests were carried out using a universal testing machine (Shimadzu AGS-10kND), at a nominal strain rate of $5.56 \times 10^{-4} \mathrm{~s}^{-1}$ (a constant cross-head speed of $0.1 \mathrm{~mm} / \mathrm{min}$ ). A non-contact extensometer based on CCD camera system was used to measure the strain during tensile tests. At least four specimens were tested for each specimen condition to verify the reproducibility of the results. The Vickers Hardness (HV) measurements were carried out using $0.89 \mathrm{~N}$ load and $5 \mathrm{~s}$ dwell time.

\section{Results}

\subsection{Microstructural characteristics of the powders}

Figure 2 shows the morphology and the microstructure of SUS304L steel powders before and after the milling. The morphology of the initial steel powder particles, powder milled for 180ks (MM180ks), and 360ks (MM360ks) are shown in Fig.2a, 2c and 2e, respectively. It can be observed that the initial powder has a spherical shape and smooth surface appearance, whereas the milled powders have irregular shape and rough surface. It can also be noticed that the milled powder particles become increasingly distorted with an increase in milling time. It is worth emphasizing that the milling 
conditions were optimized in such a way that the MM processing did not lead to any fracturing or agglomeration due to cold welding of the powder particles. Therefore, such a change in morphology can be attributed to the increasing levels of accumulated plastic deformation of powder particles with increasing milling time.

The microstructures of the cross-section of the initial powder and the powders milled for $180 \mathrm{ks}$ and $360 \mathrm{ks}$ are shown in Fig.2b, $2 \mathrm{~d}$ and $2 \mathrm{f}$, respectively. It can be noticed that the initial powder has rather homogeneous contrast across the entire particle section, while the milled powders demonstrate contrast substantially varying between the periphery and the core areas. Namely, the formation of a thin bright-contrast layer near the surface of the powder particles is evident. Moreover, it can also be noted that the thickness of the surface layer increases with an increase of milling time, compare Figs. $2 \mathrm{~d}$ and $2 \mathrm{f}$, while the contrast of the core area does not change appreciably.

\subsection{Microstructural characteristics of the sintered steel compacts}

Figure 3 shows the microstructure of the sintered SUS304L compacts prepared from the initial and the milled powders. As can be observed in Fig.3a, some residual pores remain in the sintered compacts prepared from the initial powder. These are usually attributed to regular spherical shape and a large particle size of a powder [33]. It can 
also be clearly observed that a reasonably homogeneous coarse-grained structure, with an average grain size of approximately $19.5 \mu \mathrm{m}$, is formed in the sintered compacts prepared from the initial powder (Fig.3a and 3b).

On the contrary, sintering of the milled powders results in near-full density compacts, as can be seen in Figs.3c and 3e. It can also be noticed that the microstructures of the MM180ks and MM360ks powder compacts consist of two different types of areas: (i) coarse-grained areas, or "core", and (ii) ultrafine-grained areas, or "shell" (Fig.3c-f). Furthermore, the sintered compacts prepared from the milled powders have a peculiar microstructure wherein the core areas are enclosed in a three-dimensional continuously connected network of the shell areas, which is termed as "harmonic structure".

From Figure 3, it can also be noticed that an increasing milling time leads to an increased shell fraction in the sintered compacts (Fig.3c-f). Figure 4 and Table 2 summarize quantitatively the effect of milling time on the shell fraction and grain size in the sintered SUS304L compacts. It can be noted that the sintered compacts prepared from the initial powder have a homogeneous microstructure with an average grain size of approximately $\mathrm{d}_{\mathrm{c}}=19.5 \mu \mathrm{m}$ within $15-25 \mu \mathrm{m}$ variation limits. Mechanical milling of the powders leads to the formation of two distinctly different populations of grain sizes in the final compacts, i.e. the bimodal grain structure consisting of ultrafine-grained 
"shell" and coarse-grained "core" areas. In the first, "coarse-grained" population, the grain size characteristics are similar to those of the initial powder compacts, and vary insubstantially with MM processing. The second, "ultrafine-grained" population, has an average grain size of approximately $\mathrm{d}_{\mathrm{s}}=2.0 \mu \mathrm{m}$ within $1-4 \mu \mathrm{m}$ variation limits. It is stabilised already after the MM processing for $180 \mathrm{ks}$, and further processing leads to a decrease in the variation limits with a minor change in the average grain size. Along with these modest changes in the grain size characteristics of both the populations, the shell area fraction increases significantly from $21 \%$ to $42 \%$ with an increase of milling time from $180 \mathrm{ks}$ to $360 \mathrm{ks}$.

\subsection{Mechanical properties of harmonic-structured compacts}

Figure 5 shows the Vickers Hardness values of sintered compacts prepared from the initial and the milled powders. In the harmonic-structured compacts, the hardness measurements were carried out separately in the shell and the core areas. It can be noted that the hardness values of the compacts from the initial powder are at the same level as the hardness of the core areas in the harmonic-structured compacts. Figure 5 indicates that at the selected MM conditions, HV in the harmonic-structured SUS304L steel is almost independent on milling time, and the hardness of the shell becomes nearly $40 \%$ 
higher than that of the core. Although it appears that the average hardness value in the shell increases with an increase of MM time, effectively it remains within the statistical variation limits, and should rather be attributed to the accuracy of the measurement indenter positioning.

The results of tensile testing along with indicative data on SUS304L steel after different types of processing from the literature are summarized in Fig. 6 and Table 2. The inferior ductility of compacts sintered from the initial powder can be attributed to the presence of significant amount of porosity compared to their fully dense alternatives produced by the ingot metallurgy route. Figure 6 shows the nominal stress - nominal strain curves, obtained from tensile tests of SUS304L steel specimens having various structures. It is interesting to note, that the $0.2 \%$ proof stress and the ultimate tensile strength (UTS) of the harmonic-structured SUS304L steel (Specimen 1: MM180ks powder compact; Specimen 2: MM360ks powder compact) are superior to its coarse-grained counterpart (Specimen 3: Bulk). At the same time, it has the uniform and the total elongations only 20 per cent. lower than that in the coarse-grained material. Moreover, the harmonic-structured compacts obtained from the MM360ks powder have higher strength, longer strain hardening stage, and more than twice higher elongation to failure when compared to the homogenous ultrafine-grained SUS304L steel (Specimen 
4), as can be seen in Fig.6. Homogeneous materials having finest, 0.2-0.5 $\mu \mathrm{m}$, grain size obtained by ECAP [8] or thermal cycling [11] have higher strength, but extremely inferior ductility characteristics when compared with the harmonic-structured one, as can be seen from Table 2.

Therefore, it can be concluded that the harmonic-structured SUS304L steel demonstrates winning combination of high strength, large uniform elongation and large total elongation to failure.

\subsection{Fractography analysis}

Figure 7 shows representative fracture surfaces of tensile specimens prepared from the MM180ks powders. The presence of a significant amount of cracks (debonding) can be clearly observed on the fracture surface in Fig.7a. Moreover, the morphology of fracture surface in the harmonic-structured compacts is dominated with dimples, Fig.7b. In general, two different morphologies were apparent: (i) coarse dimples corresponding to the cores and (ii) finer dimples arose from the fracture of shell region. In addition, the cracks are formed in the vicinity of core/shell interface, as can be seen in Fig. $7 \mathrm{~b}$. 


\section{Discussion}

\subsection{The control of microstructure in harmonic-structured SUS304L steel during}

\section{fabrication}

The experimental results presented above clearly demonstrate that the harmonic structure in the sintered compacts is derived from the presence of a shell-and-core bimodal structure in the mechanically milled powders. Moreover, in contrast to a more typically observed in a literature on bimodal grain structure, the harmonic one has a specific periodic, or harmonic, arrangement. Such an arrangement is made possible by the selected approach and a strict control of the fabrication parameters. First, it is important to form core/shell structure in the metallic powder particles. This can be achieved by mechanical milling, as in the present study, or by other high-energy particle deformation techniques like jet milling, etc. Second, the particles having the core/shell structure should be sintered with minimal porosity, while the ultrafine-grained structure in the particle shell should be preserved to form a continuously connected network in the sintered compacts. This can be achieved by spark plasma sintering, as in the present study, or by other advanced sintering techniques like hot-roll sintering, etc.

A bright-contrast area at the periphery of mechanically milled powder particles that can be found in SEM micrographs, Fig.2, indicates the thickness of UFG layer (the shell 
area). It is produced by severe plastic deformation on the surface of SUS304L particles from collisions with balls during $\mathrm{MM}$ processing. Detailed investigation of the mechanisms of UFG structure formation is out of the scope of the present paper, and therefore reader is referred for that information elsewhere $[4,5,34,35]$. The thickness of this shell area, and hence the fraction of UFG structure, is controlled by such parameters of mechanical milling as (i) ball diameter (and hence weight), (ii) ball to powder ratio, (iii) milling time, and (iv) milling speed, temperature and atmosphere. It is important to ensure that the impact from collisions between balls and particles leads to a limited-depth penetration of plastic deformation, and processing time is sufficient to produce the deformed UFG layer of even thickness. Of course, the fracture of particles should also be avoided. Appropriate selection of these parameters allows to control the process of mechanical milling precisely, and to produce the required gradient of microstructure in the processed powder particles.

A technique and parameters for the sintering of MM powders should be tailored to ensure appropriate green compaction and then inter-particle bonding, while minimizing the processes of grain growth in the shell area. These can usually be achieved through the utilization of high hydrostatic pressure, fast heating/cooling rates, and high temperature applied for a short time. A technique perfectly satisfying all these criteria is 
spark plasma sintering, and therefore it was used in the present investigation. Hot-roll sintering is also an excellent technique for this purpose since, in addition to hydrostatic pressure, it imparts shear deformation thus accelerating inter-particle bonding. In both these techniques, the control of holding temperature and time allows to adjust the balance of core/shell fractions, and to minimize the level of residual porosity.

In the present study, a significant amount of residual porosity is found in the compacts sintered from the initial non-processed powder, see Fig.3a. By contrast, the MM-processed powders sintered in essentially same conditions demonstrate virtually nil porosity in their microstructure, Fig. $3 \mathrm{c}$ and $3 \mathrm{e}$. These results indicate that, in addition to the formation of harmonic structure, the pre-processing by mechanical milling leads to the improvement of powder sinterability and density.

\subsection{Correlation between microstructure, mechanical properties and fracture mechanism in harmonic-structured SUS304L steel}

The microhardness measurements along with the SEM observations demonstrate that the harmonic-structured SUS304L compacts possess a microstructure wherein softer coarse-grained core areas are enclosed in a three-dimensional continuously connected network of harder ultrafine-grained shell. Qualitatively, such a variation in hardness 
well resembles the Hall-Petch relationship. Similar behaviour has $0.2 \%$ proof stress, which monotonically increases with an increase of the shell fraction, see Fig.8.

However, ultimate tensile strength and uniform elongation demonstrate different non-monotonic behaviour. Figure 8 reveals the dependencies of strength and uniform elongation in SUS304L steel on the volume fraction of shell. It can be seen that the highest ultimate tensile strength of $744 \mathrm{MPa}$ is reached in the material with a shell fraction of $41 \%$. Further increase of the fraction of UFG area to $100 \%$ only decreases the value of UTS a little. The uniform elongation in 100\% UFG-structured SUS304L steel is less than a half of that in the $100 \%$ coarse-grained material. However, this dependence is non-monotonic in between these two extremes of the microstructural states. Namely, an increase in the shell fraction from $21 \%$ to $41 \%$, leads to a substantial increase in uniform elongation as well as in the $0.2 \%$ proof stress. Therefore, the harmonic-structured SUS304L steel having $41 \%$ of the UFG shell area in the microstructure is found in the present study to be optimal for the balance of strength and ductility.

One more important conclusion can be made analysing a qualitatively different behaviour of the tensile testing characteristics in Fig.8. It can be seen that the rates of increase in $0.2 \%$ proof stress and UTS with an increase of the fraction of UFG structure are very different. This leads to a decrease of the difference between these two strength 
characteristics, which is also accompanied by a decrease of uniform elongation. Such behaviour can be attributed to a limited capacity of UFG materials produced by SPD for dislocation storage, and hence very limited strain hardening and uniform elongation. These are well-known drawbacks of ultrafine-grained and nano-crystalline microstructures [3]. In the harmonic-structured material, the capacity for strain hardening and uniform elongation as well as total elongation will depend on the balance between the shell and core fractions. This dependence can be as simple as the rule of mixtures, for example, or much more complicated. This question will be explored in detail in further investigations.

As shown in Fig.7, it is thought that the larger surface dimples indicate that the core (CG) regions underwent significantly more plastic strain than shell (UFG) regions. Due to different ductility of shell and core regions, the cracks initiate at the core/shell interface more easily than in the centre of the shell or core region for the harmonic-structured SUS304L steel. It is also worthy to note that multiple cracks are apparent near the fracture surface, which indicates that the cracks initiation is not localized to a single site, but they rather form at multiple places near the fracture tip in harmonic-structured SUS304L steel.

The unique mechanical behaviour of the harmonic structured material can be 
attributed to its peculiar microstructure consisting of a three-dimensional core/shell network structure. At the early stages of deformation, the onset of plastic flow in the softer CG "core" regions is delayed by still elastic deformation in the stronger UFG "shell" network structure. This leads to the elevated values of Yield Strength in the harmonic-structured materials compared to their coarse-grained counterpart. At subsequent deformation stages, the strength of softer cores approaches the levels of that in shell due to a higher level of total plastic strain accumulated in the cores. However, even minute differences in the levels of accumulated strain between core and shell regions cause a rise of back-stress on their interface. This back-stress plays important role at later deformation stages when global tensile stress level approaches the value of Ultimate Tensile Strength of the material. Such a level of global stress initiates strain localisation quickly followed by necking and then fracture in homogeneous or simply heterogeneous materials. By contrast, the presence of continuous network of shell and the back-stress in the harmonic-structured materials leads to a more even distribution of stress, and the localisation of strain becomes delayed. As a result, the strain hardening stage becomes extended, and necking is delayed. These allow the harmonic structured materials to capitalise on the best of two worlds of high-ductility capacity of coarse grains, and high strength of UFG structures. 


\subsection{Benefits of harmonic structure design for the control of SUS304L steel performance}

As summarized in Table 2, harmonic-structured SUS304L steel samples with superior mechanical properties were fabricated in the present study. The selected approach allows to control the microstructural characteristics, and thus the material performance, in a rather wide range. This design concept appears to be winning from the point of view of precisely tailorable balance between the strength and ductility characteristics. Namely, the harmonic-structured material significantly exceeds the mechanical characteristics of SUS304L steel commercially supplied by different manufacturers [36, 37]. Compared to the ordinary products with a homogeneous grain size of $\sim 35 \mu \mathrm{m}$ produced by the ingot metallurgy route, the harmonic-structured one possesses slightly inferior ductility, but nearly 30 percent higher $0.2 \%$ proof and ultimate tensile strengths.

To the best of the authors knowledge, the record level of strength $(0.2 \%$ proof stress $=$ $1013 \mathrm{MPa}$ and UTS $=1094 \mathrm{MPa})$ was achieved in ultrafine-grained $(<\mathrm{d}>=0.2-0.5 \mu \mathrm{m})$ SUS304L steel by ECAP processing at $973 \mathrm{~K}$ [8]. A similar level of the strength and the microstructure characteristics was produced by a thermal cycling at 1173-1223 K [11]. However, the ductility characteristics were so low (the uniform and total elongations down 
to $3 \%$ and $12 \%$, respectively) that further processing as well as potential applications of such materials were largely compromised. By contrast, the harmonic-structured SUS304L steel exceeds these ductility characteristics by far $(68 \%$ and $80 \%$, respectively), which opens up a much wide avenue for the applications of this material.

Furthermore, the selected powder metallurgy based approach for the fabrication of harmonic-structured materials allows the consolidation of mechanically milled powders into final products. This may further reduce the cost of industrial manufacturing processes based on this approach, which makes the proposed concept of material design even more attractive for commercial applications.

\section{Conclusions}

In the present work, SUS304L stainless steel compacts with harmonic structure design were prepared by controlled mechanical milling of PREPed pre-alloyed powders followed by spark plasma sintering. The microstructure evolution and the mechanical properties of the sintered SUS304L compacts were analysed. Based on this analysis, the following conclusions can be drawn:

(1) A heterogeneous shell-and-core microstructure with bimodal grain size distribution can be produced in SUS304L steel powder particles by mechanical milling. The 
parameters of microstructure in the milled powder can be controlled by such processing in a rather wide range. Spark plasma sintering was successfully utilized for the consolidation of mechanically milled powders, which produced harmonic-structured material.

(2) The microstructure of this material comprised of soft core areas with coarse structure enclosed into three-dimensional network of hard ultrafine-grained structure. A balance between the shell and core fractions is an extremely important parameter for the control of the mechanical performance of harmonic-structured SUS304L steel.

(3) The harmonic-structured SUS304L steel demonstrates a superior combination of high strength, large uniform elongation, and large total elongation. Such a combination makes this material as well as the proposed approach of its fabrication very attractive for commercial applications.

\section{Acknowledgement}

This research was supported by the Japan Science and Technology Agency (JST) under Collaborative Research Based on Industrial Demand "Heterogeneous Structure Control:

Towards Innovative Development of Metallic Structural Materials", and by the 
Grant-in-Aid for Scientific Research on Innovative Area, "Bulk Nanostructured Metals", through MEXT, Japan (contract No. 22102004). These supports are gratefully appreciated.

\section{References}

[1] H. Gleiter, Acta Mater., 48 (2000) 1-29.

[2] N. Hansen, Scripta Mater., 51 (2004) 801-806.

[3] M.A. Meyers, A. Mishra, D.J. Benson, Prog. Mater. Sci., 51 (2006) 427-556.

[4] R.Z. Valiev, M.J. Zehetbauer, Y. Estrin, H.W. Höppel, Y. Ivanisenko, H. Hahn, G. Wilde, H.J. Roven, X. Sauvage, T.G. Langdon, Adv. Eng. Mater., 9 (2007) 527-533.

[5] Y. Estrin, A. Vinogradov, Acta Mater., 61 (2013) 782-817.

[6] X.H. Chen, J. Lu, L. Lu, K. Lu, Scripta Mater., 52 (2005) 1039-1044.

[7] N. Kamikawa, T. Sakai, N. Tsuji, Acta Mater., 55 (2007) 5873-5888.

[8] C.X. Huang, G. Yang, Y.L. Gao, S.D. Wu, Z.F. Zhang, Mat. Sci. Eng. A, 485 (2008) 643-650.

[9] S. Qu, C.X. Huang, Y.L. Gao, G. Yang, S.D. Wu, Q.S. Zang, Z.F. Zhang, Mat. Sci. Eng. A, 475 (2008) 207-216.

[10] I. Gutierrez-Urrutia, D. Raabe, Scripta Mater., 66 (2012) 992-996.

[11] B. Ravi Kumar, D. Raabe, Scripta Mater., 66 (2012) 634-637.

[12] D. Orlov, A. Pougis, R. Lapovok, L.S. Tóth, I.B. Timokhina, P.D. Hodgson, A. Haldar, D. Bhattacharjee, Metall. Mater. Trans. A, 44 (2013) 4346-4359.

[13] E. Ma, Scripta Mater., 49 (2003) 663-668.

[14] N. Tsuji, N. Kamikawa, R. Ueji, N. Takata, H. Koyama, D. Terada, ISIJ Int., 48 (2008) 1114-1121.

[15] N. Tsuji, Y. Ito, Y. Saito, Y. Minamino, Scripta Mater., 47 (2002) 893-899.

[16] H. Jin, D.J. Lloyd, Scripta Mater., 50 (2004) 1319-1323.

[17] B. Srinivasarao, K. Oh-ishi, T. Ohkubo, T. Mukai, K. Hono, Scripta Mater., 58 (2008) 759-762.

[18] H.W. Höppel, M. Korn, R. Lapovok, H. Mughrabi, J. Phys. Conf. Ser., 240 (2010) 012147.

[19] S. Zherebtsov, E. Kudryavtsev, S. Kostjuchenko, S. Malysheva, G. Salishchev, Mat. Sci. Eng. A, 536 (2012) 190-196.

[20] D. Orlov, H. Fujiwara, K. Ameyama, Mater. Trans., 54 (2013) 1549-1553. 
[21] S. Joshi, K. Ramesh, B. Han, E. Lavernia, Metall. Mater. Trans. A, 37 (2006) 2397-2404.

[22] Y. Wang, M. Chen, F. Zhou, E. Ma, Nature, 419 (2002) 912-915.

[23] D. Witkin, Z. Lee, R. Rodriguez, S. Nutt, E. Lavernia, Scripta Mater., 49 (2003) 297-302.

[24] H. Fujiwara, T. Sekiguchi, K. Ameyama, Int. J. Mater. Res., 6 (2009) 796-799.

[25] G.J. Fan, H. Choo, P.K. Liaw, E.J. Lavernia, Acta Mater., 54 (2006) 1759-1766.

[26] G. Dirras, J. Gubicza, S. Ramtani, Q.H. Bui, T. Szilágyi, Mat. Sci. Eng. A, 527 (2010) 1206-1214.

[27] T. Sekiguchi, K. Ono, H. Fujiwara, K. Ameyama, Mater. Trans., 51 (2010) 39-45.

[28] Z. Zhang, M. Rifai, H. Kobayakawa, O.P. Ciuca, H. Fujiwara, A. Ueno, K. Ameyama, Mater. Trans., 53 (2012) 109-115.

[29] Y. Yamada, H. Fujiwara, H. Miyamoto, K. Ameyama, J. Jpn. Soc. Powder and Powder Metall., 60 (2013) 160-166.

[30] H. Fujiwara, T. Kawabata, H. Miyamoto, K. Ameyama, Mater. Trans., 54 (2013) 1619-1623.

[31] O.P. Ciuca, M. Ota, S. Deng, K. Ameyama, Mater. Trans., 54 (2013) 1629-1633.

[32] H. Fujiwara, R. Akada, A. Noro, Y. Yoshita, K. Ameyama, Mater. Trans., 49 (2008) 90-96.

[33] P. Suri, R.P. Koseski, R.M. German, Mat. Sci. Eng. A, 402 (2005) 341-348.

[34] H. Fujiwara, H. Inomoto, R. Sanada, K. Ameyama, Scripta Mater., 44 (2001) 2039-2042.

[35] D. Orlov, N. Kamikawa, N. Tsuji, Philos. Mag., 92 (2012) 2329-2350.

[36] http://www.susjis.info/austenitic/sus3041.html, Last accessed on June 22, 2013.

[37] http://www.3161-stianless.com/Stainless-steel/JIS-G4303-SUS304L.html, Last accessed on June 22, 2013. 


\section{List of Table and Figure Captions}

Table 1 Chemical composition of SUS304L PREP powders (mass\%) used in the present investigation.

Table 2 Quantitative characteristics of the mechanical properties of SUS304L steel after different kinds of thermo-mechanical processing.

Fig.1 Schematic of a harmonic-structured material.

Fig.2 SE-SEM micrographs illustrating shape (a,c,e) and BSE-SEM micrographs revealing microstructure $(b, d, f)$ of SUS304L steel powder particulates in the initial condition and after mechanical milling: (a,b) Initial powder; (c,d) MM180ks powder; (e,f) MM360ks powder.

Fig.3 Microstructures of SUS304L compacts sintered from (a,b) initial, (c,d) MM180ks, and (e,f): MM360ks powders: (a), (c), (e) are BSE-SEM micrographs, and (b), (d), (f) are EBSD image quality maps overlaid with HABs.

Fig.4 Diagram illustrating the dependence of grain size and shell fraction in the sintered SUS304L compacts on the time of mechanical milling. 
Fig.5 Diagram illustrating the dependence of Vickers Hardness of the sintered SUS304L compacts on the time of mechanical milling.

Fig.6 Representative tensile stress-strain curves of SUS304L steel having various structures; $d_{c}$ and $d_{s}$ stand for average grain size in the core and shell areas, respectively, while $\mathrm{S}_{\mathrm{f}}$ for the fraction of shell area.

Fig.7 SE-SEM micrographs of fracture surfaces of sintered MM180ks powder compact after tensile testing: (a) Low magnification and (b) High magnification of cracks.

Fig.8 Dependence of strength and uniform elongation in SUS304L steel on shell fraction. 
Table 1 Chemical composition of SUS304L PREP powders (mass\%) used in the present investigation.

\begin{tabular}{cccccccc}
\hline $\mathrm{C}$ & $\mathrm{Si}$ & $\mathrm{Mn}$ & $\mathrm{P}$ & $\mathrm{S}$ & $\mathrm{Ni}$ & $\mathrm{Cr}$ & $\mathrm{Fe}$ \\
\hline 0.05 & 0.28 & 1.37 & 0.032 & 0.025 & 8.2 & 18.6 & Bal. \\
\hline
\end{tabular}


Table 2 Quantitative characteristics of mechanical properties of SUS304L steel after different kinds of thermo-mechanical processing.

\begin{tabular}{|c|c|c|c|c|c|c|c|c|}
\hline \multirow{2}{*}{ No. } & \multirow{2}{*}{ Processing** } & \multirow{2}{*}{$\begin{array}{c}\sigma_{0.2} * \\
{[\mathrm{MPa}]}\end{array}$} & \multirow{2}{*}{$\begin{array}{l}\sigma_{\mathrm{UTS}} * \\
{[\mathrm{MPa}]}\end{array}$} & \multirow{2}{*}{$\begin{array}{l}\varepsilon_{\mathrm{u}}^{*} \\
{[\%]}\end{array}$} & \multirow{2}{*}{$\begin{array}{c}\varepsilon_{\mathrm{t}}^{*} \\
{[\%]}\end{array}$} & \multicolumn{2}{|c|}{$\begin{array}{c}\text { Average grain size }[\mu \mathrm{m}], \\
\text { (fraction) }\end{array}$} & \multirow{2}{*}{ Ref. } \\
\hline & & & & & & bulk or core & shell & \\
\hline 1 & MM180ks+SPS1173K & 328 & 690 & 61.8 & 80.1 & $16.8(79 \%)$ & $2.0(21 \%)$ & Present \\
\hline 2 & MM360ks+SPS1173K & 382 & 744 & 65.6 & 80.3 & $17.6(59 \%)$ & $1.5(41 \%)$ & Present \\
\hline 3 & Bulk & 250 & 601 & 79.4 & 94.3 & $\begin{array}{c}35.0 \\
(100 \%)\end{array}$ & --- & Present \\
\hline 4 & ECAP at $1073 \mathrm{~K}$ & 580 & 710 & 30.0 & 37.0 & $\begin{array}{l}0.2-1.0 \\
(100 \%)\end{array}$ & --- & [9] \\
\hline 5 & $\begin{array}{l}\text { Initial Powder } \\
\text { +SPS1173K }\end{array}$ & 260 & 516 & 44.6 & 48.4 & $\begin{array}{c}19.7 \\
(100 \%)\end{array}$ & --- & Present \\
\hline 6 & ECAP at $973 \mathrm{~K}$ & 1013 & 1094 & 3.0 & 12.0 & $\begin{array}{l}0.2-0.5 \\
(100 \%)\end{array}$ & --- & [8] \\
\hline 7 & $\begin{array}{l}\text { Thermal cycling at } \\
1173-1223 \mathrm{~K}\end{array}$ & 902 & 1082 & 5.0 & 16.0 & $\begin{array}{l}0.2-0.5 \\
(100 \%)\end{array}$ & --- & {$[11]$} \\
\hline
\end{tabular}

$*_{\sigma_{0.2}}$ stands for $0.2 \%$ proof stress; $\sigma_{U T S}$ for ultimate tensile stress; $\varepsilon_{\mathrm{u}}$ for uniform elongation and $\varepsilon_{\mathrm{t}}$ for total elongation.

**MM means mechanical milling of SUS304L powder; SPS - spark plasma sintering; and ECAP - equal channel angular pressing. 


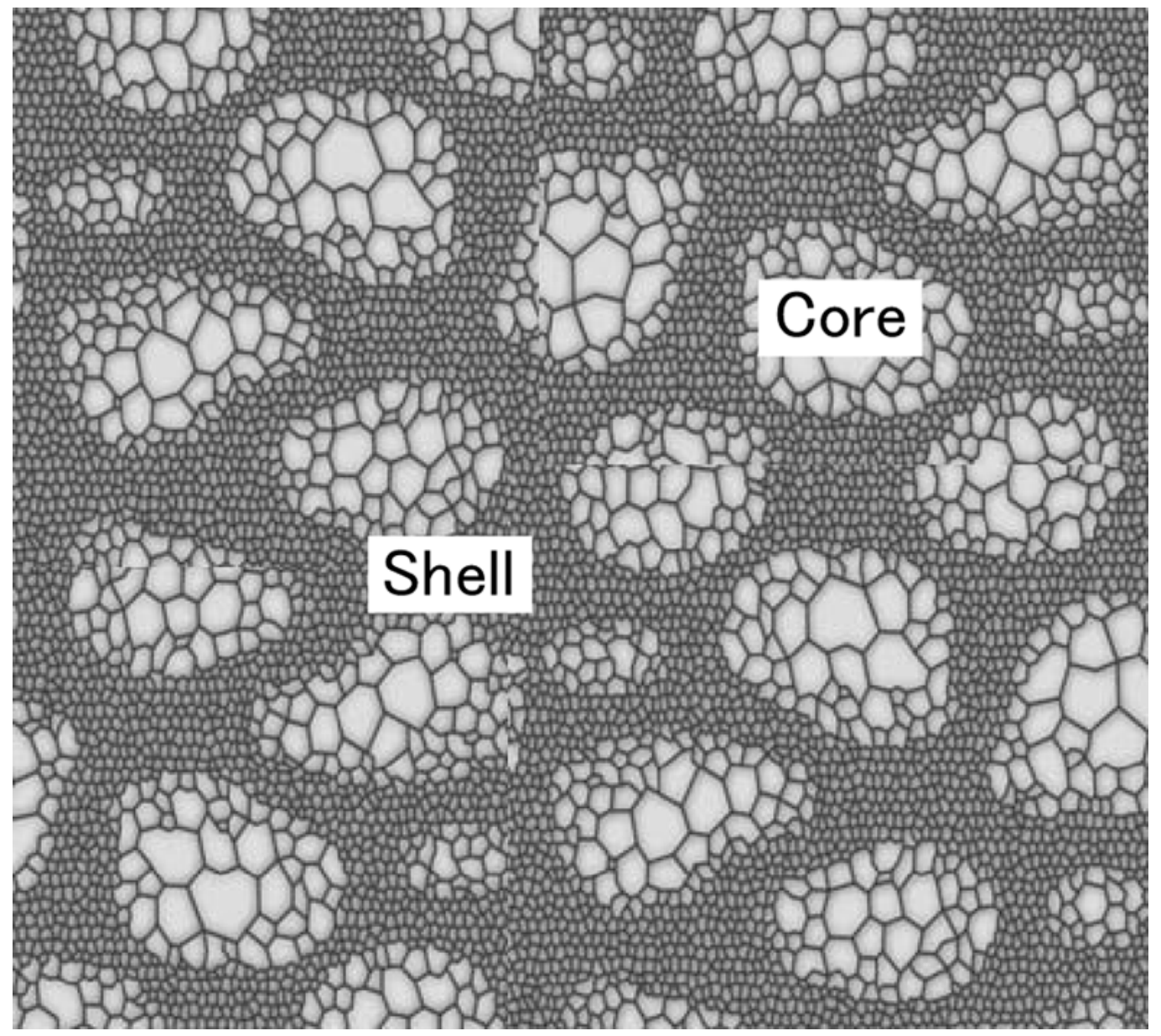

Fig.1 Schematic of a harmonic-structured material. 

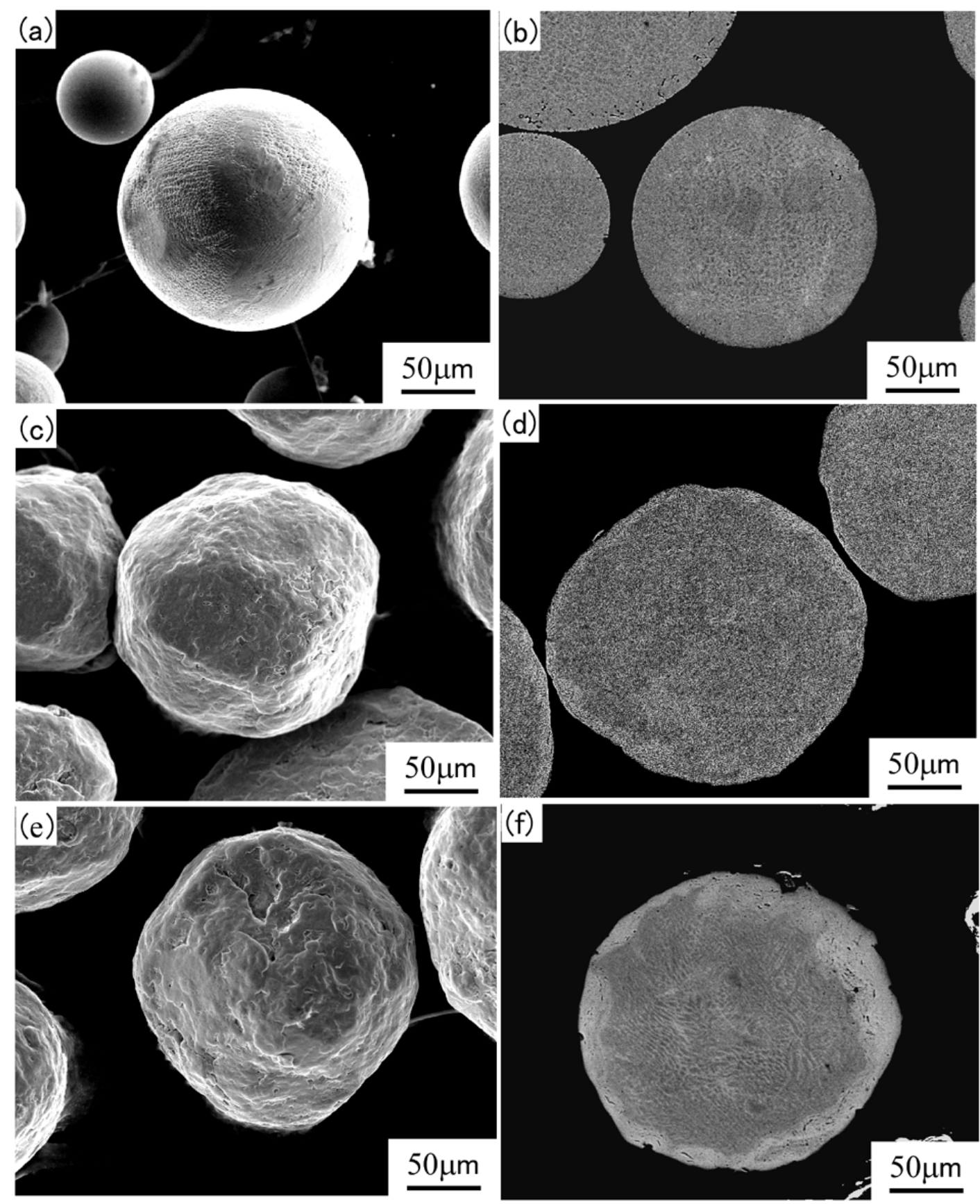

Fig.2 SE-SEM micrographs illustrating shape (a,c,e) and BSE-SEM micrographs revealing microstructure $(\mathrm{b}, \mathrm{d}, \mathrm{f})$ of SUS304L steel powder particulates in the initial condition and after mechanical milling: (a,b) Initial powder; (c,d) MM180ks powder; $(\mathrm{e}, \mathrm{f}) \mathrm{MM} 360 \mathrm{ks}$ powder. 

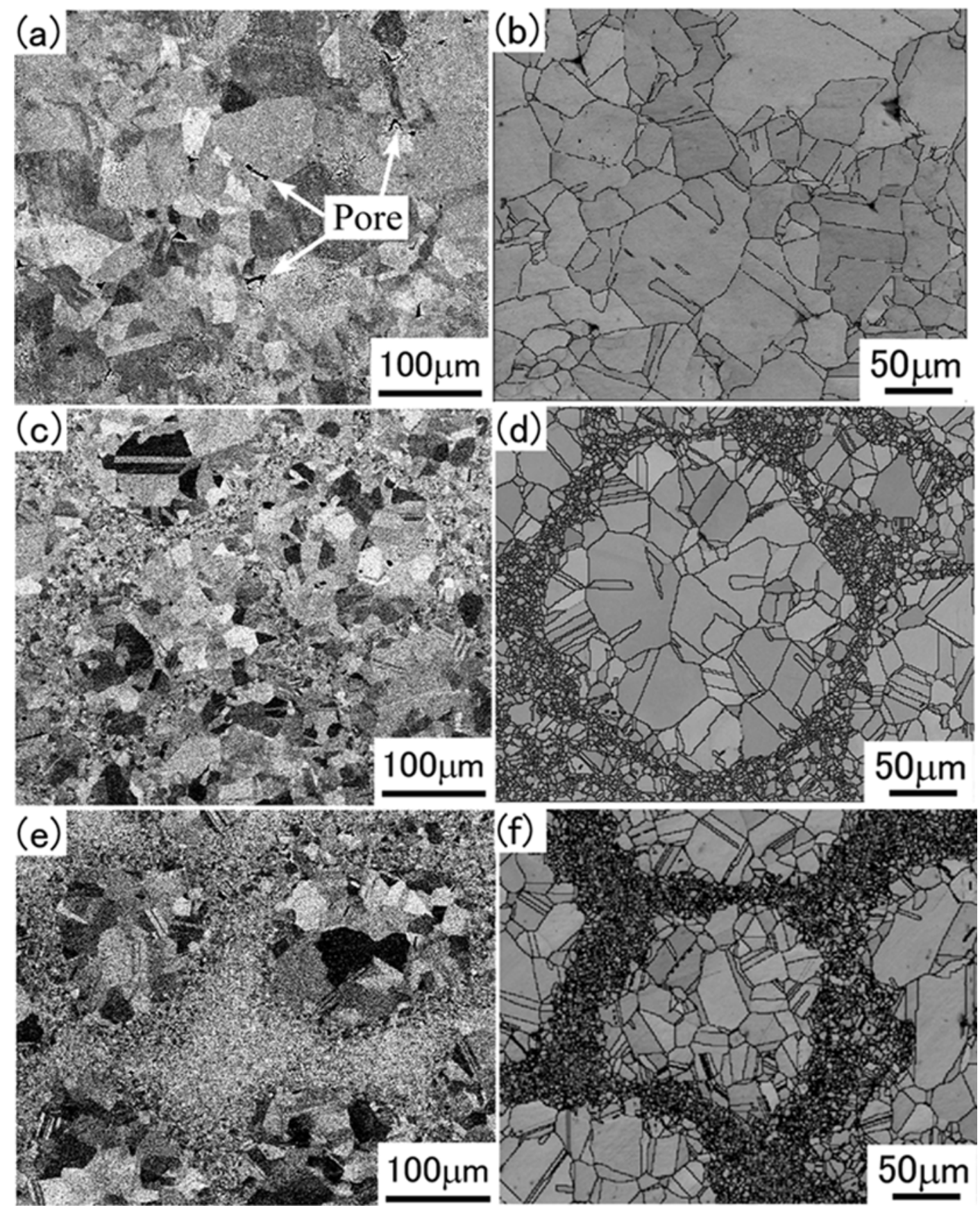

Fig.3 Microstructures of SUS304L compacts sintered from (a,b) initial, (c,d) MM180ks, and (e,f): MM360ks powders: (a), (c), (e) are BSE-SEM micrographs, and (b), (d), (f) are EBSD image quality maps overlaid with HABs. 


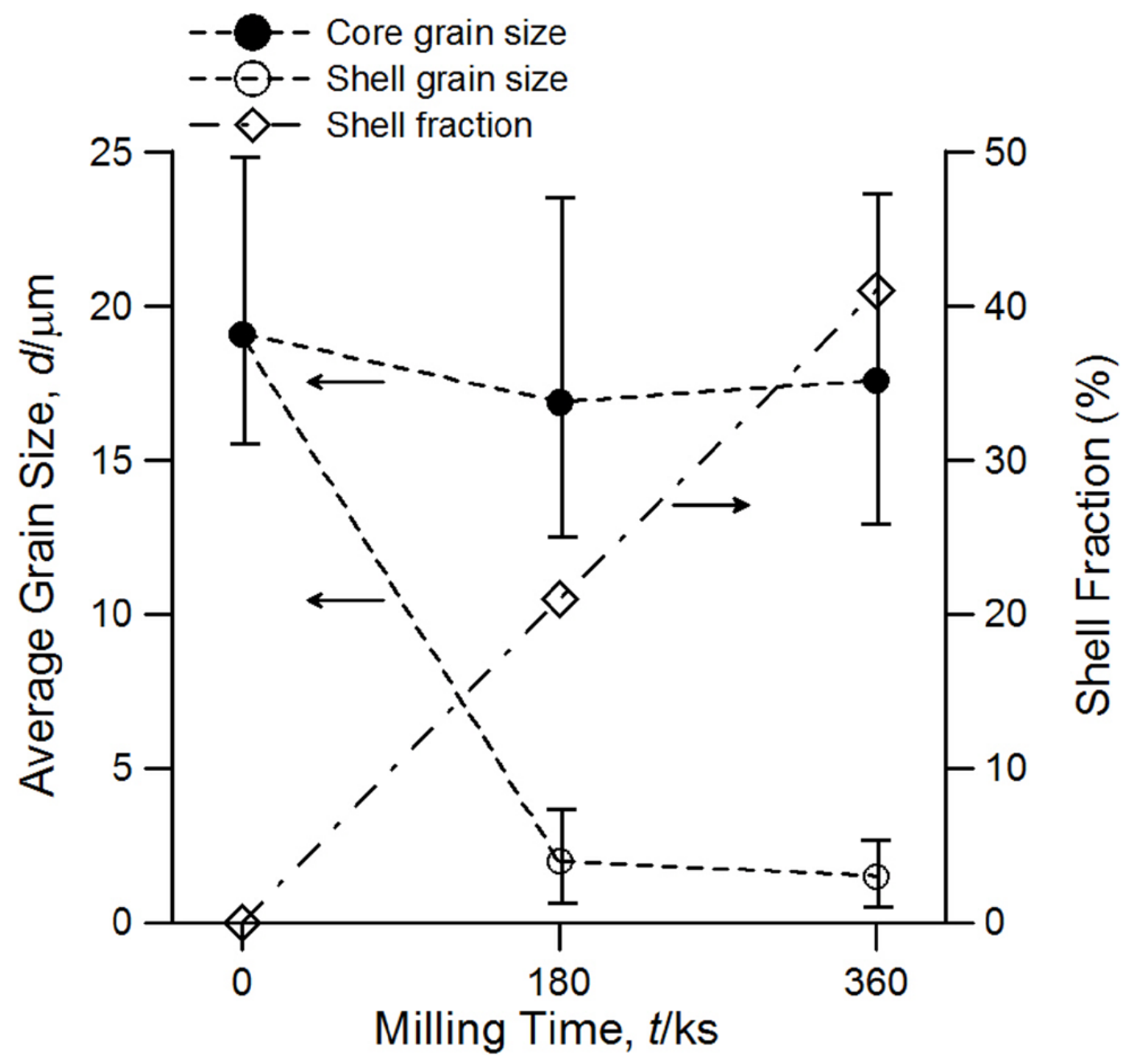

Fig.4 Diagram illustrating the dependence of grain size and shell fraction in the sintered SUS304L compacts on the time of mechanical milling. 


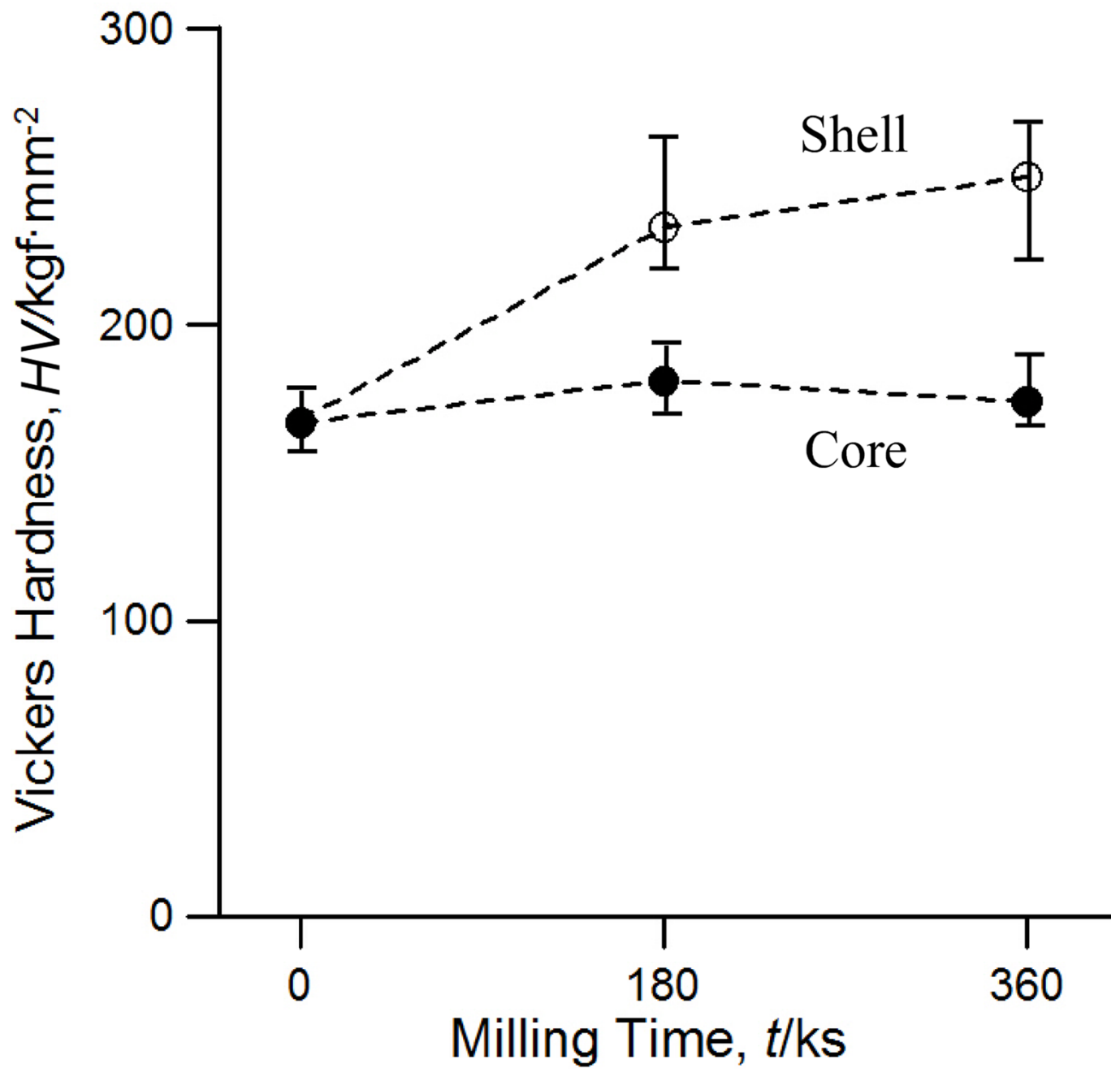

Fig.5 Diagram illustrating the dependence of Vickers Hardness of the sintered SUS304L compacts on the time of mechanical milling. 


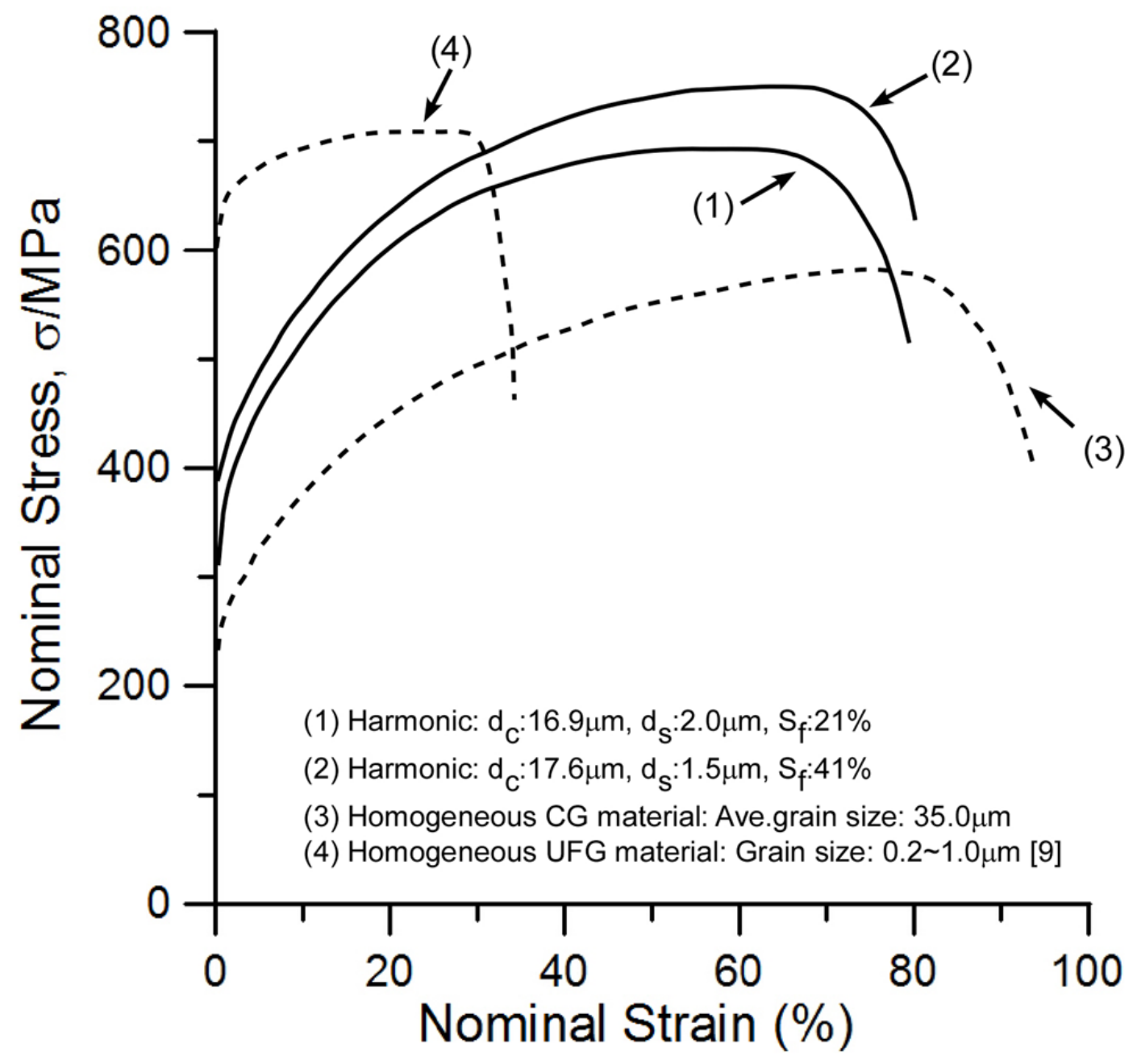

Fig.6 Representative tensile stress-strain curves of SUS304L steel having various structures; $d_{c}$ and $d_{s}$ stand for average grain size in the core and shell areas, respectively, while $\mathrm{S}_{\mathrm{f}}$ for the fraction of shell area. 

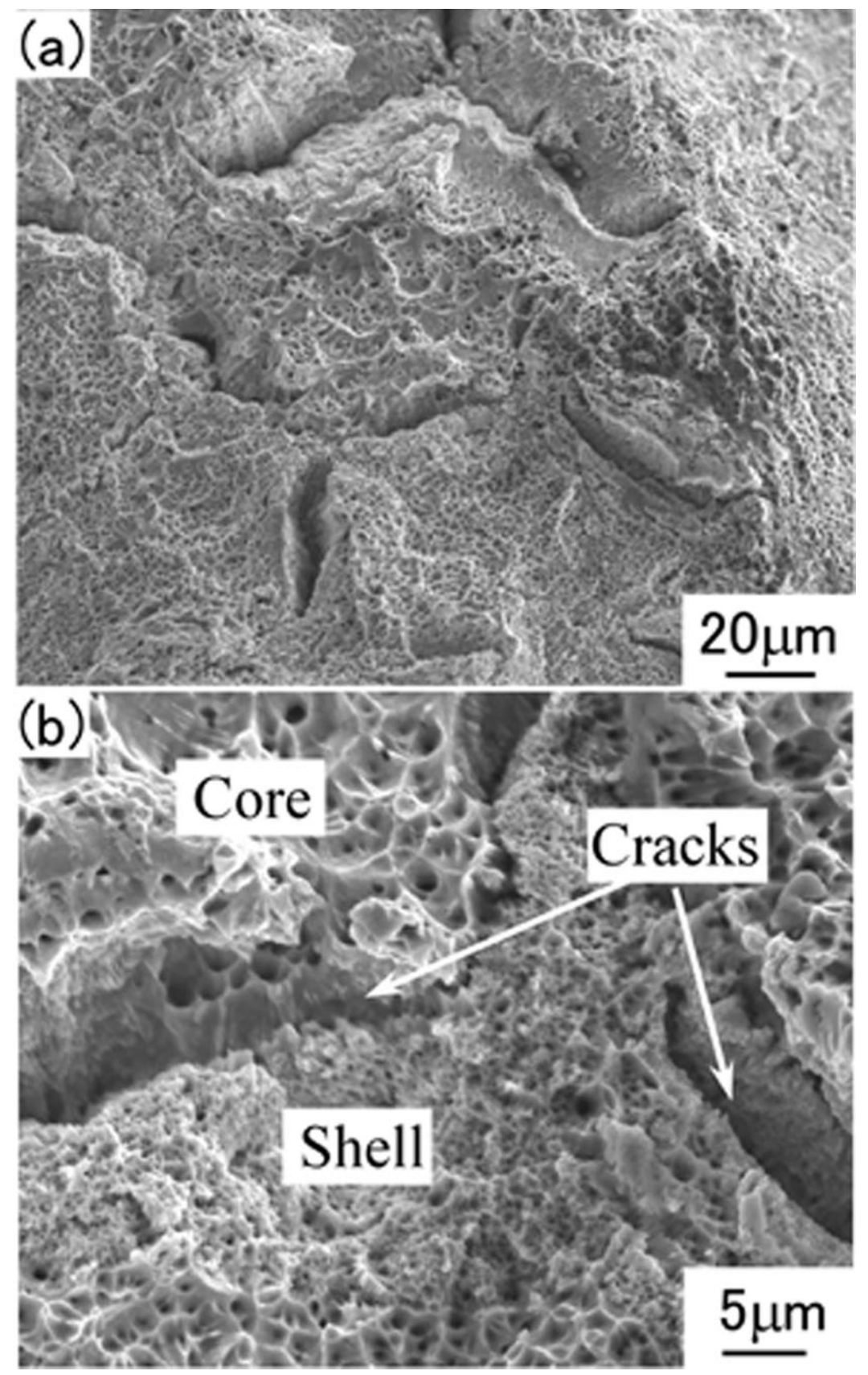

Fig.7 SE-SEM micrographs of fracture surfaces of sintered MM180ks powder compact after tensile testing: (a) Low magnification and (b) High magnification of cracks. 


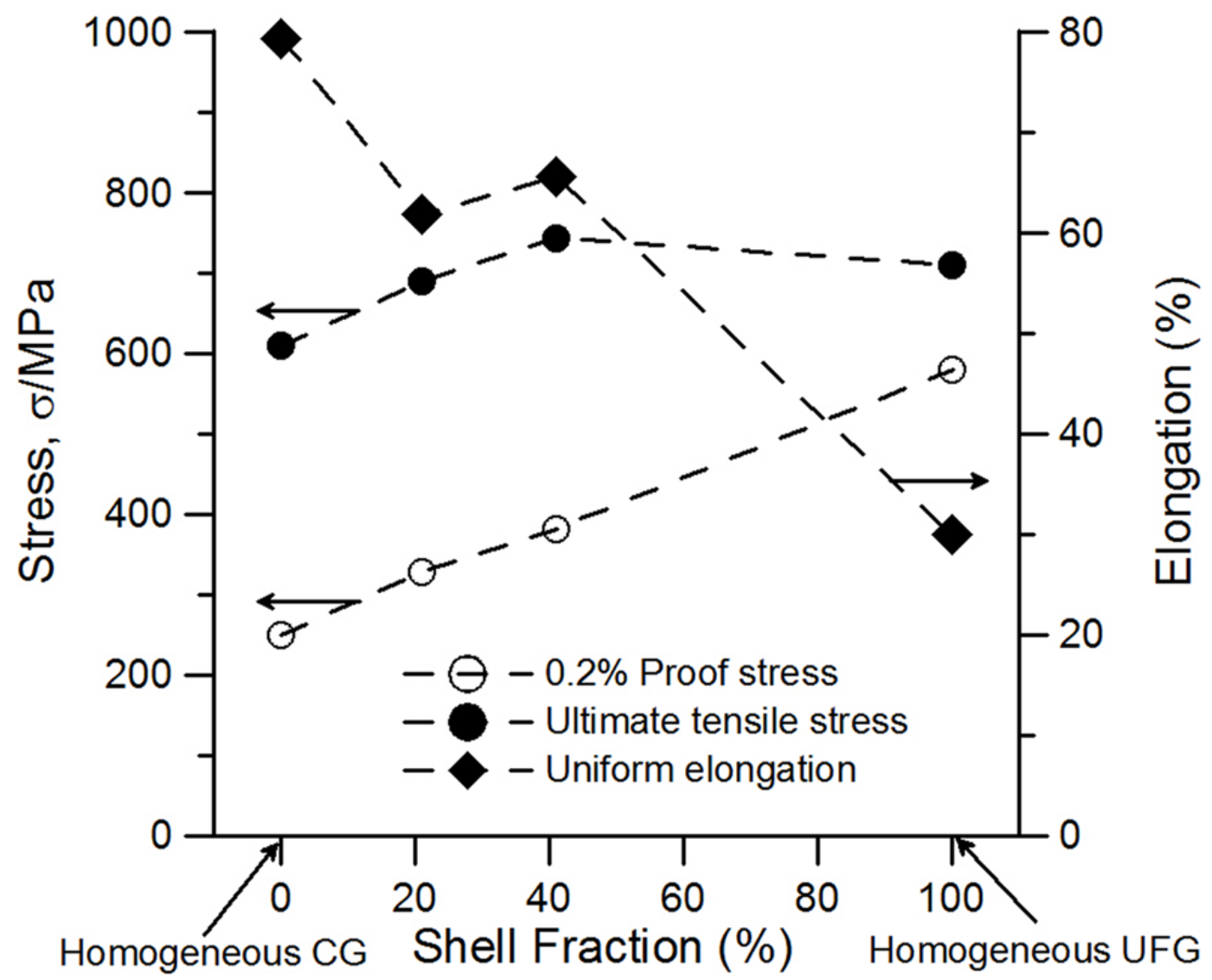

Fig.8 Dependence of strength and uniform elongation in SUS304L steel on shell fraction. 